\title{
Proximity of the home to a cooling tower and risk of non-outbreak legionnaires' disease
}

\author{
Rajinder S Bhopal, Ronald J Fallon, Elaine C Buist, Roger J Black, James D Urquhart
}

\begin{abstract}
Objective-To study the source of non-outbreak legionnaires' disease, particularly the role of cooling towers, by comparing the locations of patients' homes in relation to the location of cooling towers.

Design-Retrospective, descriptive study of a case series of patients with legionnaires' disease ill between 1978 and 1986 and, for comparison, a case series of patients with lung cancer. A prospectively developed register and interview based survey provided data on the location of cooling towers.

Setting - The city of Glasgow.

Patients-134 patients aged 14-84 with legionnaires' disease during $1978-86$ and 10159 patients with lung cancer during the same period.

Main outcome measures-The locations of patients' homes and cooling towers as defined by postcodes, which provided map grid references accurate to $10 \mathrm{~m}$; numbers of expected and observed cases of legionnaires' disease in census enumeration districts; and distance of enumeration districts from the nearest cooling tower as defined by five distance categories.
\end{abstract}

Results-Most cooling towers were in or near the city centre or close to the River Clyde, as were the places of residence of patients with community acquired, non-travel, non-outbreak legionnaires' disease $(n=107)$. There was an inverse association between the distance of residence from any cooling tower and the risk of infection, the population living within $0.5 \mathrm{~km}$ of any tower having a relative risk of infection over three times that of people living more than $1 \mathrm{~km}$ away. There was no such association with respect to travel related legionnaires' disease, and for lung cancer the association was weak (relative risk $\leqslant 1 \cdot 2$ in any distance group).

Conclusion-In Glasgow cooling towers have been a source of infection in two outbreaks of legionnaires' disease and, apparently, a source of non-outbreak infection also. Better maintenance of cooling towers should help prevent non-outbreak cases. This method of inquiry should be applied elsewhere to study the source of this and other environmentally acquired disease.

\section{Introduction}

Legionnaires' disease is a bacterial pneumonia acquired by inhaling aerosol contaminated by legionellas. The important known sources of infective aerosol are evaporative cooling systems (referred to in this paper as cooling towers) and hot water systems. In Britain most clusters of infection have been associated with hot water systems. ${ }^{1}$ With regard to evaporative cooling systems these are of two types: evaporative condensers and wet type cooling towers. Essentially these systems eject heat into the atmosphere as evaporated water, but most of the coolant water is recirculated. Legionellas thrive in this environment and may be aerosolised in high concentration, particularly in poorly maintained systems.

In many outbreaks of legionella infection the source is not discovered. For example, in only seven of 26 outbreaks listed by Band and Fraser was the source known. ${ }^{2}$ Furthermore, most cases of infection are sporadic, and in these cases the source is seldom found or sought. Although the risk factors for sporadic cases are similar to those for outbreak cases, ${ }^{3}$ the natural assumption that the sources of outbreak and sporadic infection are the same needs to be tested. ${ }^{14}$

Based on cases that occurred in 1984 (the year of a community acquired outbreak ${ }^{5}$ ) Bhopal and Fallon reported an association between the location of cooling towers in Glasgow and the residence of patients with non-outbreak disease. ${ }^{6}$ This led to the hypothesis that cooling towers were important sources of both outbreak related and non-outbreak related disease. The accuracy of the data on the location of cooling towers, however, was unknown. (We prefer the term "non-outbreak" to "sporadic," though in published research sporadic is usually used to mean nonoutbreak. We define sporadic as referring to cases that were not clustered in time and space and non-outbreak as referring simply to cases that were not recognised as being part of a cluster.) This report describes the relation between the location of cooling towers in Glasgow and the location of patients' homes in cases of legionnaires' disease that occurred between 1978 and 1986 using more advanced statistical techniques and verified data on the location of cooling towers. Two important alternative explanations were tested. These were $(a)$ that the association between the location of cooling towers and place of residence in cases reflected a higher susceptibility rather than exposure in populations living near cooling towers (the susceptibility hypothesis); and (b) that people living near cooling towers were more likely to be admitted to hospital and tested for legionnaires' disease (the differential testing hypothesis).

Sources of data and methods

CASE LISTING, DETAILS OF PATIENTS, AND

CLASSIFICATION OF CASES

Lists of cases of legionnaires' disease compiled at the department of laboratory medicine, Ruchill Hospital, Glasgow, were cross checked with a list compiled by the Communicable Disease Scotland Unit (which is responsible for disease surveillance and where laboratory returns are collated) and a master list of possible cases prepared. The department of laboratory medicine at Ruchill Hospital has acted as a primary and reference diagnostic facility for legionella infections in Scotland since 1977, and most if not all laboratories in Scotland have used the facilities. ${ }^{7}$ Probably most if not all positive results from laboratories elsewhere have been submitted to the department for confirmation. The laboratory methods have been reported. ${ }^{8-10}$ The tests done include the indirect fluorescence antibody test - firstly, with polyvalent heat killed antigens and then, for positive serum, monovalent heat killed antigens (the range being extended as new legionella serogroups have been discovered); culture with buffered charcoal yeast extract agar; the direct fluores- 
cence antibody test; and assay for urinary antigen (none of the patients in this study were diagnosed on the basis of that test). The validity of the heat killed antigens has been described. ${ }^{8112}$ The quality of the serological tests has been monitored by cross checking results with antigens prepared by the United States Centres for Disease Control and, in recent years, with antigens from the Public Health Laboratory Service, Colindale.

The background and clinical details were in most cases obtained from laboratory request forms and, for cases occurring after mid-1984, from replies to a questionnaire to consultants. Details recorded by RJF during telephone and written communication about cases were also used. Rarely, computerised, microfiche Scottish morbidity records provided the only source of clinical (diagnostic codes) and address information.

Hospital consultants and general practitioners were sent a computer printout giving the name, address, date of birth, hospital number, and date of onset of illness of patients in their charge. Their view on the validity of the diagnosis was sought. General practitioners were also asked about the patient's occupation and whether the patient had been in hospital or travelled abroad before the illness. When permission was obtained from general practitioners to do so patients were written to; this allowed a further check on the address and both the travel and hospitalisation history. In some cases hospital notes were examined by RSB (with permission from consultants).

Based on the case definition of legionnaires' disease set out in the appendix each patient was assigned as having had a probable case (henceforth called case), possible case, or unlikely case. This was done independently by using the general practitioners' replies, the consultants' replies, and opinions based on laboratory held data. In cases of disagreement the evidence was reassessed by RSB and a final assignment made in the light of the varying opinions and the case definition. In addition, patients were classified as nosocomial cases if there was any history of visiting a hospital in the 10 days preceding illness; as travel associated cases if they had travelled outside Scotland in the 10 days preceding illness; and as outbreak related cases if they were part of the two outbreaks described in Scotland during $1978-86 .{ }^{513}$ The remaining cases, referred to as community acquired, non-travel, non-outbreak cases, comprised the group of principal interest.

\section{LOCATION OF COOLING TOWERS IN GLASGOW}

The details of a study on the location and maintenance of cooling towers have been published. ${ }^{14}$ Essentially, over several years beginning in 1984 environmental health officers actively sought out premises with cooling towers, questionnaires were sent to large premises in the city, and information was obtained from the city's planning department. The impetus to locate cooling towers was provided by the two outbreaks of legionnaires' disease. ${ }^{513}$ One environmental health officer verified the existence of cooling towers.

\section{ASSESSING SUSCEPTIBILITY HYPOTHESIS}

Hospital discharge data (Scottish morbidity records) for malignant neoplasm of the trachea, bronchus, and lung (ICD (ninth revision) code 162) held by the Common Services Information and Statistics Division were used to derive an indicator of susceptibility, as this disease shares several of the risk factors associated with legionnaires' disease-for example, it is commoner in older people, men, and smokers. The discharge records were matched by name and date of birth to reduce hospital episodes to records of individual cases.
ASSESSING DIFFERENTIAL TESTING HYPOTHESIS

Serological tests were chosen as an indicator of diagnostic activity. The number of requests from each of the Glasgow hospitals by year were obtained from the laboratory register at Ruchill Hospital and related to the numbers of discharges and deaths with respect to pneumonia in each hospital (unpublished hospital inpatient statistics) and numbers of cases of legionnaires' disease.

Two ratios were calculated: number of tests to number of cases of pneumonia, and number of tests to number of cases of legionnaires' disease. In a hospital where serological tests are commonly done, perhaps routinely for respiratory disorders, the ratio of number of tests to number of cases of pneumonia would be fairly high. Assuming that the proportion of cases of respiratory disorders that were legionnaires' disease was uniform across hospitals, the ratio of number of tests to number of cases of legionnaires' disease would also be fairly high. But if the proportion of cases which were legionnaires' disease was higher than average in one hospital the ratio of number of tests to number of cases of legionnaires' disease might be average or even lower than average. These ratios can show whether a hospital has a high or low threshold for testing and whether this is a result of an underlying higher than average incidence of disease.

Laboratories in Glasgow hospitals were contacted and information obtained about their use of the acting reference laboratory.

\section{GEOGRAPHICAL ANALYSIS}

The addresses of patients and cooling towers were converted manually to seven unit postcodes and, by using the postcode directory, ${ }^{15}$ converted to grid references with a resolution of $10 \mathrm{~m}$. These were mapped by using a computer mapping package. ${ }^{16}$

The relation between the location of home residence in cases and the location of premises with cooling towers was studied first visually, then statistically. The statistical analysis entailed calculating for each census enumeration district the expected numbers of cases of travel associated and community acquired, non-travel, non-outbreak legionnaires' disease by applying age, sex, and year specific rates for Glasgow city to the age and sex stratified population of these areas (from the 1981 census data). Observed numbers of cases in each enumeration district were found by linking postcodes with enumeration districts by using the postcode directory. This process was repeated for the lung cancer data.

Each enumeration district was then categorised according to the distance from the population weighted centroid of the district to the nearest cooling tower. This was done separately for each of the years 1978 to 1986 and took account of which towers were known to exist during the particular year, based on the age of the towers at the time of the survey. The distance categories were $\leqslant 0.25 \mathrm{~km},>0.25 \mathrm{~km}$ to $\leqslant 0.5 \mathrm{~km}$, $>0.5 \mathrm{~km}$ to $\leqslant 0.75 \mathrm{~km},>0.75 \mathrm{~km}$ to $\leqslant 1.0 \mathrm{~km}$, and $>1.0 \mathrm{~km}$. The numbers of observed and expected cases in each of these categories during 1978 to 1986 were found by summing the individual year totals. The relative risks of living within each of the four categories $\leqslant 1.0 \mathrm{~km}$ from a cooling tower compared with living outside the $1 \mathrm{~km}$ zone were estimated using the Mantel-Haenszel odds ratio. ${ }^{17}$

\section{Results}

\section{BACKGROUND INFORMATION}

Between 1978 and 1986 there were 210 possible cases of legionnaires' disease in the city of Glasgow. Thirty two were associated with the 1984 outbreak, ${ }^{5}$ five with the 1985 outbreak, ${ }^{13}$ and seven were in patients who 
had visited a hospital in the 10 days before illness. Of the remaining 166 cases, 134 met the diagnostic criteria; all these patients had a clinical history of acute pneumonia or a lower respiratory tract infection and met laboratory criteria as summarised in table I. There was close agreement between the diagnostic classification of these 134 cases with regard to the views, based on clinical records, of general practitioners (available for 82 cases) and consultants (available for 70 cases) and the views of RSB based on laboratory held data. General practitioners and RSB

TABLE I-Laboratory basis for 134 cases of legionnaires' disease that met diagnostic criteria

\begin{tabular}{|c|c|c|c|c|}
\hline $\begin{array}{l}\text { Highest titre } \\
\text { recorded }\end{array}$ & $\begin{array}{l}\text { No culture } \\
\text { positive }\end{array}$ & $\begin{array}{l}\text { No positive } \\
\text { on direct } \\
\text { fluorescence } \\
\text { antibody test }\end{array}$ & $\begin{array}{l}\text { No serologically } \\
\text { positive only }\end{array}$ & $\begin{array}{c}\text { All } \\
\text { patients }\end{array}$ \\
\hline \multicolumn{5}{|c|}{ Patients with fourfold rise in titre ( $n=92)$} \\
\hline 64 & - & - & 5 & 5 \\
\hline 128 & 2 & - & 19 & 21 \\
\hline 256 & 3 & - & 25 & 28 \\
\hline 512 & 4 & - & 26 & 30 \\
\hline 1024 & - & - & 7 & 7 \\
\hline$\geqslant 2048$ & - & - & 1 & 1 \\
\hline \multicolumn{5}{|c|}{ Patients with fourfold fall in titre $(n=3)$} \\
\hline 256 & - & - & 1 & 1 \\
\hline 512 & - & - & 2 & 2 \\
\hline \multicolumn{5}{|c|}{ Patients with static titre $(n=39)$} \\
\hline 0 & $3^{\star}$ & 2 & - & $3^{\star}$ \\
\hline 64 & 1 & - & - & 1 \\
\hline 128 & - & 1 & - & 1 \\
\hline 256 & - & - & 12 & 12 \\
\hline 512 & - & - & 19 & 19 \\
\hline 1024 & - & - & 3 & 3 \\
\hline Total & $13^{\star}$ & 3 & 120 & 134 \\
\hline
\end{tabular}

${ }_{\star}^{\star}$ Two patients were positive both on direct fluorescence antibody test and on culture.

TABLE II - Relation between distance of patients' homes from cooling tower and incidences of legionnaires' disease and lung cancer

\begin{tabular}{|c|c|c|c|}
\hline Study group & $\begin{array}{c}\text { Distance of home } \\
\text { from nearest cooling } \\
\text { tower }(\mathrm{km})^{\star}\end{array}$ & $\begin{array}{l}\text { No of cases } \\
\text { observed } \\
\text { (No } \\
\text { expected) }\end{array}$ & $\begin{array}{c}\text { Relative risk of } \\
\text { disease compared } \\
\text { with group living } \\
>1.0 \mathrm{~km} \text { from nearest } \\
\text { cooling tower }(95 \% \\
\text { confidence interval) }\end{array}$ \\
\hline Legionnaires disease: no history of travel abroad $(n=107)$ & $\begin{array}{l}\leqslant 0.25 \\
>0.25 \text { to } \leqslant 0.5 \\
>0.5 \text { to } \leqslant 0.75 \\
>0.75 \text { to } \leqslant 1.0 \\
>1.0\end{array}$ & $\begin{array}{l}12(4 \cdot 4) \\
28(13 \cdot 2) \\
15(17 \cdot 9) \\
14(17 \cdot 9) \\
38(53 \cdot 7)\end{array}$ & $\begin{array}{l}3.89(1.92 \text { to } 7.70) \\
3.00(1.79 \text { to } 5.02) \\
1.19(0.62 \text { to } 2.22) \\
1.11(0.57 \text { to } 2.11) \\
1.00\end{array}$ \\
\hline Legionnaires' disease: history of travel abroad $(n=27)$ & $\begin{array}{l}\leqslant 0.25 \\
>0.25 \text { to } \leqslant 0.5 \\
>0.5 \text { to } \leqslant 0.75 \\
>0.75 \text { to } \leqslant 1.0 \\
>1.0\end{array}$ & $\begin{array}{c}0(1 \cdot 0) \\
2(3 \cdot 1) \\
6(4 \cdot 3) \\
4(4 \cdot 3) \\
15(14 \cdot 4)\end{array}$ & $\begin{array}{l}0.62(0.10 \text { to } 2.81) \\
1.33(0.46 \text { to } 3.66) \\
0.89(0.25 \text { to } 2 \cdot 86) \\
1.00\end{array}$ \\
\hline Lung cancer (ICD code $162 ; n=10159)$ & $\begin{array}{l}\leqslant 0 \cdot 25 \\
>0 \cdot 25 \text { to } \leqslant 0.5 \\
>0.5 \text { to } \leqslant 0.75 \\
>0.75 \text { to } \leqslant 1 \cdot 0 \\
>1.0\end{array}$ & $\begin{array}{c}475(407) \\
1339(1252) \\
1760(1711) \\
1613(1679) \\
4972(5109)\end{array}$ & $\begin{array}{l}1.20(1.09 \text { to } 1.32) \\
1.10(1.03 \text { to } 1.17) \\
1.06(1.00 \text { to } 1.12) \\
0.99(0.93 \text { to } 1.04) \\
1.00\end{array}$ \\
\hline
\end{tabular}

*The denominator population living within each distance category varied from year to year owing to the varying The denominator population living within each distance category varied from year to year owing to the varying numbers of cooling towers in each year. The average denominator populations were as follows: 404341 people lived $0.75 \mathrm{~km}$ away, 84466 lived between 0.25 and $0.5 \mathrm{~km}$ away, and 27884 lived less than $0.25 \mathrm{~km}$ away. agreed on $93 \%$ of occasions, and consultants and RSB agreed on $96 \%$ of occasions. Ninety two patients had a fourfold rise in antibody titre and three a fourfold fall. One hundred and twenty six (94\%) infections were with Legionella pneumophila of serogroup 1; two each with serogroups 2, 4, and 5; and one each with serogroups 3 and 8 .

The mean age of the 134 patients was 56 years (range 14-84) and the male to female ratio was $1 \cdot 9$. In 27 cases the infection had been acquired abroad, leaving 107 community acquired, non-travel, non-outbreak cases. There was a wide fluctuation in the annual number of these cases: seven occurred in 1978; 15 in 1979, three in 1980, five in 1981, three in 1982, 12 in 1983, 32 in 1984, 29 in 1985, and one in 1986.

\section{LOCATION OF COOLING TOWERS AND RESIDENCE OF} PATIENTS

The figure shows that most premises with cooling towers known to be present in 1984 were near the city centre or the River Clyde. The same was true of the patients' homes in many of the 107 community acquired, non-travel, non-outbreak cases of legionnaires' disease. The pattern of distribution of residences in cases judged visually was similar to this in $1978,1979,1983,1984$, and 1985 (map available on request). It was observed for men and women and for those of retirement age $(>65)$ and working age. Visually there was no association between the location of cooling towers and the location of patients' residences in the 27 travel associated cases (map not shown; available on request).

Table II shows that the relative risk of community acquired, non-travel, non-outbreak legionnaires' disease was over 3.0 in people living within $0.5 \mathrm{~km}$ of a cooling tower compared with people living more than $1 \mathrm{~km}$ away. There was a definite dose-response effect. The association was evident for the years 1978 , $1979,1983,1984$, and 1985, the observed to expected numbers of cases in these years among people residing within $0.5 \mathrm{~km}$ of a cooling tower being $4.5,2.9,3.2$, 2.5 , and 1.7 respectively. There was no association with respect to travel associated infection. The association between cooling tower location and location of home residence in cases of lung cancer though statistically significant, was weak (relative risks $1 \cdot 1$ and $1 \cdot 2$ for patients living $>0.25$ to $\leqslant 0.5 \mathrm{~km}$ and $\leqslant 0.25 \mathrm{~km}$ from a cooling tower respectively). Based on the formula attributable risk $=$ (proportion of population exposed $\times$ (relative risk -1$) /($ population exposed $\times$ (relative risk $-1)+1$, and assuming that the association is causal, $28 \%$ of the incidence of non-outbreak legionnaires' disease would be attributable to cooling tower sources.

REQUESTS FOR SEROLOGY IN RELATION TO PNEUMONIA AND LEGIONNAIRES' DISEASE BY HOSPITAL

Table III lists the main Glasgow hospitals in rank order of distance from Central Station in the city centre

TABLE III - Relation between numbers of serological tests requested and numbers of cases of legionnaires' disease and pneumonia in acute intake hospitals in Greater Glasgow Health Board, 1978-86

\begin{tabular}{|c|c|c|c|c|c|c|c|}
\hline Hospital & $\begin{array}{c}\text { Approximate } \\
\text { compass direction } \\
\text { from city centre }\end{array}$ & $\begin{array}{c}\text { Approximate } \\
\text { distance from } \\
\text { city centre }(\mathrm{km})^{\star}\end{array}$ & $\begin{array}{l}\text { No of tests } \\
\text { requested }\end{array}$ & $\begin{array}{l}\text { No of cases of } \\
\text { legionnaires' } \\
\text { disease }\end{array}$ & $\begin{array}{c}\text { No of cases of } \\
\text { pneumonia }\end{array}$ & $\begin{array}{l}\text { No of tests } \\
\text { requested per } \\
\text { case of } \\
\text { legionnaires' } \\
\text { disease }\end{array}$ & $\begin{array}{l}\text { No of tests } \\
\text { requested per } \\
\text { case of } \\
\text { pneumonia }\end{array}$ \\
\hline Glasgow Royal Infirmary & East north east & 1.4 & 2353 & 74 & 1573 & 32 & 1.5 \\
\hline Western Infirmary & West north west & $2 \cdot 8$ & 832 & 15 & 772 & 55 & $1 \cdot 1$ \\
\hline Ruchill Hospital & North west north & $3 \cdot 0$ & 1644 & 56 & 1621 & 29 & 1.0 \\
\hline Victoria Infirmary & South & $3 \cdot 4$ & 371 & 12 & 1402 & 31 & $0 \cdot 3$ \\
\hline Belvidere Hospital & East south east & $3 \cdot 8$ & 592 & 24 & 1133 & 25 & 0.5 \\
\hline Gartnavel & North west & $4 \cdot 2$ & 516 & 6 & 1035 & 86 & 0.5 \\
\hline Stobhill Hospital & North north east & $4 \cdot 4$ & 672 & 9 & 1900 & 75 & $0 \cdot 4$ \\
\hline Southern General $t$ & West & $5 \cdot 6$ & 1059 & 16 & 1854 & 66 & $0 \cdot 6$ \\
\hline Knightswood Hospital & North west & $6 \cdot 0$ & 294 & 5 & 730 & 59 & $0 \cdot 4$ \\
\hline Total & & & 8333 & 217 & 12020 & 38 & $0 \cdot 7$ \\
\hline
\end{tabular}

*City centre taken as Central Station. †South Glasgow hospitals. 


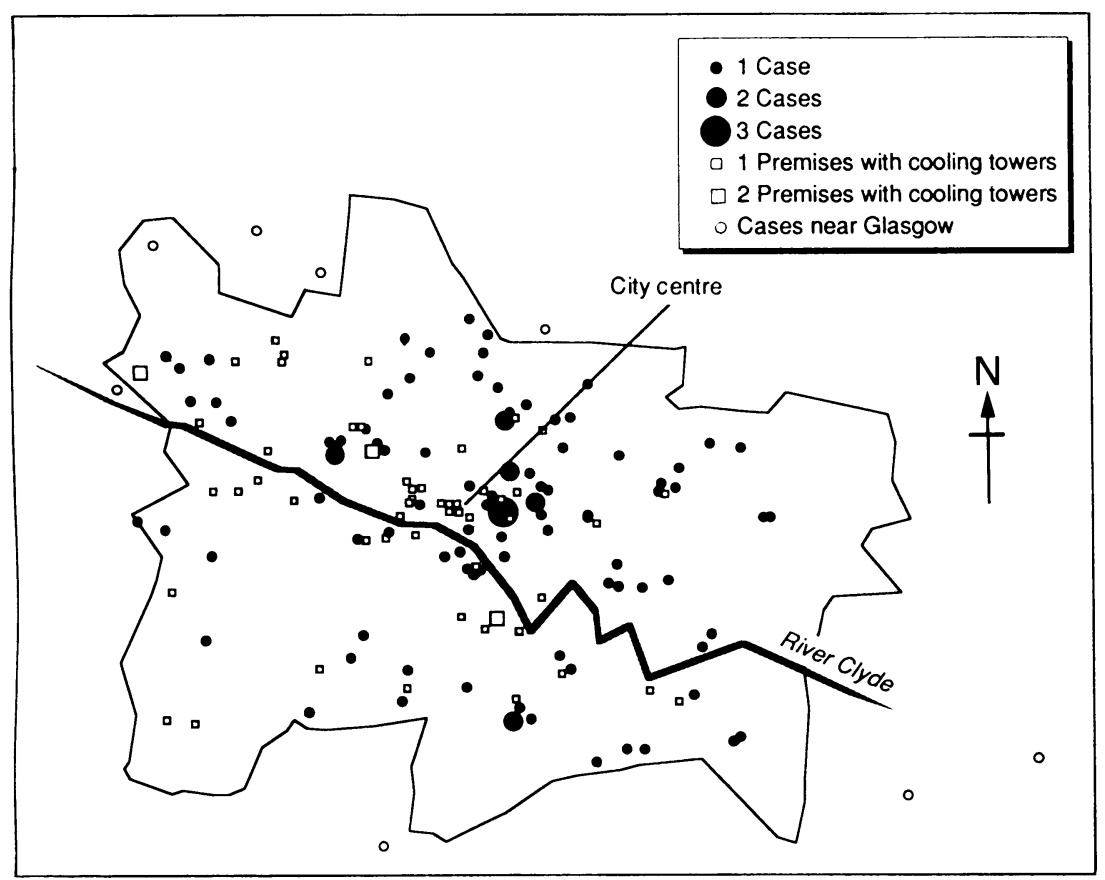

Map of locations of cooling towers known to exist in city of Glasgow in 1984 in relation to residence of patients with community acquired, non-travel, non-outbreak legionnaires' disease during 1978-86

and provides data on the relation between numbers of serological tests requested and numbers of cases of legionnaires' disease and pneumonia. The three hospitals nearest the city centre had the highest ratios of tests requested to cases of pneumonia and hence the highest tendency to test for legionnaires' disease. The ratio of tests requested to cases of legionnaires' disease, however, was below average in two of these three hospitals, indicating that the incidence of the disease in these hospitals was higher than average. The hospitals distant from the city centre had lower than average ratios of numbers of tests requested to cases of pneumonia, but in most instances ratios of tests requested to cases of legionnaires' disease were higher than average, indicating that the incidence of the disease in these hospitals was lower than average.

Year by year analysis of these ratios by hospital based on cases of pneumonia in people aged 15-74 indicated that the ratio of tests requested to cases of pneumonia rose sharply in hospitals where the diagnosis was frequently made and declined in hospitals where it was not. For example, the ratios of tests requested to cases of pneumonia in Glasgow Royal Infirmary in 1981, 1982, 1983, 1984, 1985, and 1986 were $0 \cdot 5,0 \cdot 95,1 \cdot 8,3 \cdot 0,7 \cdot 9$, and $4 \cdot 2$ respectively. The 1984 and 1985 outbreaks led to a pronounced rise in testing, which started to decline in 1986 when the number of cases diminished. In the Southern General Hospital the tests to pneumonia ratios in 1983, 1984, 1985 , and 1986 were $1 \cdot 1,1 \cdot 4,4 \cdot 2$, and $2 \cdot 0$. Nosocomial cases occurred in 1985 .

All microbiology laboratories in Glasgow hospitals sent serum specimens to the department of laboratory medicine at Ruchill Hospital.

\section{Discussion}

As legionnaires' disease is acquired environmentally the risk of infection within and between communities ought to vary in time and space according to the degree of exposure to contaminated aerosol. Variation in frequency of disease between places and subgroups of populations occurs ${ }^{118}$ but has seldom been explained in terms of environmental exposure. The risk of legionella infection between 1978 and 1986 in the Glasgow population was related to the distance of the home from a cooling tower. As many people who lived more than $1 \mathrm{~km}$ away would in the course of their daily lives have come closer to cooling towers, the true risk of non-outbreak disease associated with cooling towers was probably underestimated.

The abrupt changes in the annual number of cases support the hypothesis that non-outbreak cases were linked to cooling towers. Annual fluctuations in the number of cases have occurred elsewhere in Scotland (unpublished observations) and in Scotland as a whole. ${ }^{19}$ The exposure from hot water systems would be expected to be comparatively stable but that from cooling towers is variable, being related to maintenance procedures, quality of the water, and temperature changes. Before discussing the implications of these observations we consider alternative explanations.

The observations cannot reasonably be explained by error or bias in the data or by varying case definition. As the Glasgow water supply is essentially from one source $^{20}$ there was no confounding effect in this respect. Incomplete ascertainment of cooling towers and, in particular, biased ascertainment-remains a theoretical explanation for the findings. We propose that this explanation is unlikely for the following reasons: the cooling tower register was compiled over years and not by a single survey; overregistration of premises was found $(44 \%$ of premises registered had no cooling tower but had other equipment such as humidifiers $)^{14}$; and the data on case location and cooling tower location were collected independently by different observers.

\section{ALTERNATIVE EXPLANATIONS}

There are three alternative explanations of note. Firstly, large buildings which have cooling towers may also have complex hot water systems. Could it be that people were infected by exposure to these and not the cooling towers? Aerosol from hot water systems is produced in small quantities and has not been associated with infections at a distance, ${ }^{2122}$ unlike aerosol from cooling towers. ${ }^{22}$ Hence this explanation would require that patients entered these premises; merely living close by or passing by would not suffice to cause infection. This explanation seems improbable.

Secondly, people who live near cooling towers are possibly more susceptible to infection. Cooling towers are often in the inner city or industrial areas, places where the socially deprived may live and where there is a higher prevalence of such risk factors for legionnaires' disease as smoking or chronic respiratory disease. If this "susceptibility hypothesis" were correct, however, other respiratory disorders which share the risk factors for legionnaires' disease - for example, male sex, age, and smoking-would show comparable non-causal associations with cooling towers. But this was not so, for the association in relation to lung cancer, though statistically significant, was weak (relative risk $\leqslant 1 \cdot 2$ ). (It may reflect a higher population susceptibility to lung cancer, a higher prevalence of smoking, or exposure to other carcinogens among those living around cooling towers.) On these data the susceptibility hypothesis could not explain the strong association found in regard to legionnaires' disease.

We could not obtain accurate occupational information from many patients and hence could not compare the association between social class and the risk of legionnaires' disease. (We are unaware of other studies on this subject.) We believe that our results cannot be explained as confounding by social class and were impressed by the paucity of cases in the large socioeconomically deprived housing estates of Pollock ( $6 \mathrm{~km}$ east south east of the city centre), Drumchapel ( 9 $\mathrm{km}$ north west), Easterhouse ( $9 \mathrm{~km}$ east), and Castlemilk (6 km south), which together with areas around them are characterised by a comparative lack of industry and other large non-residential buildings and 
which lie on the peripheries of the city. The explanation based on differential susceptibility is incomplete.

Thirdly, possibly people who live near cooling towers are more likely to receive a diagnosis of legionnaires' disease, either because they are more often admitted to hospital or, once there, because they are more likely to have laboratory tests. Few doctors, however, would know the location of cooling towers, so this bias could not reflect a conscious decision on their part. None the less, hospitals which serve populations who live near or adjacent to the city centre might be more attuned to the diagnosis. Analysis of the ratios of requests for serological tests to the numbers of cases of pneumonia and of requests for these tests to the numbers of cases of legionnaires' disease did not support the differential testing hypothesis. It seemed that hospitals tested more frequently but in response to a higher than average incidence, and that the higher incidence of disease near the city centre was not a result of high rates of testing by hospitals there.

\section{AEROSOL FROM COOLING TOWERS}

The most plausible explanation for the association between the locations of cooling towers and home residence in cases is that infective aerosol from cooling towers was carried moderate distances and inhaled by people living, shopping, socialising, or working nearby. Patients were not necessarily infected in their homes, though this would be compatible with past evidence of aerosol entering buildings through windows, doors, chimneys, and other air intakes. ${ }^{2324}$ Contaminated drift from cooling towers can travel hundreds of metres to cause infection..$^{532527}$ This explanation is compatible with current knowledge about drift from cooling towers, the physics of aerosol movement, ${ }^{28}$ the ecology of legionellas, and epidemiological observations. ${ }^{53-27}$

Our comparisons of relative risk were made by comparing patients resident more than $1 \mathrm{~km}$ from a cooling tower with those in four $250 \mathrm{~m}$ distance groups within $1 \mathrm{~km}$. This decision was based on the observation that bacterial infection can occur $1 \mathrm{~km}$ from a source of aerosol ${ }^{28}$ and the fact that at the time of study the maximum distance associated with airborne spread of legionnaires' disease was $900 \mathrm{~m}$ (a housebound patient). ${ }^{5}$ We have shown a non-linear dose-response, the relative risk dropping abruptly from more than $3 \cdot 0$ in people living within $0.5 \mathrm{~km}$ of a cooling tower to $1 \cdot 19$ in those living $0 \cdot 5-0.75 \mathrm{~km}$ from one. This pattern was similar to that described by Addiss et al. ${ }^{27}$ In their study of an outbreak attack rates were highest in residents living within $800 \mathrm{~m}$ of the cooling tower linked with the disease. This distance and risk relation seems compatible with aerosol movement in an urban environment, where air turbulence would encourage aerosol deposition, and accords with epidemiological observations; with two exceptions, ${ }^{527}$ drift from cooling towers has been associated with infection at a distance of about $500 \mathrm{~m}$ or less. ${ }^{23-26}$ In the exceptional cases infection may have occurred at a distance of $900 \mathrm{~m},{ }^{5}$ and possibly up to $3 \cdot 2 \mathrm{~km}$.

As the role of hot water systems has been clarified, so conventional beliefs about the transmission of legionnaires' disease have been questioned. ${ }^{29}$ Muder et al have argued that the role of cooling towers has been overemphasised..$^{29}$ In regard to non-outbreak infection the scant evidence points to hot water systems as a source. Stout et al reported two sporadic cases of the disease in which the patients had been housebound and their homes were not near cooling towers." $L$ pneumophila cultured from home water supplies was indistinguishable from strains cultured from clinical specimens. Stout et al concluded that these sporadic infections were acquired in the home. The implications of this for the prevention and investigation of legion- naires' disease were unclear, but Redd and Cohen argued that environmental interventions in the home were not justified. ${ }^{4}$

Addiss et al have reported on two patients with apparently sporadic legionnaires' disease who lived close to each other and were ill within three days of each other and who were probably infected from a cooling tower $300 \mathrm{~m}$ from their homes. ${ }^{25}$ Our observations in Glasgow indicate that for the prevention of both outbreak related and non-outbreak infection improvement in the maintenance of cooling towers should be the highest priority. Bhopal and Barr found that even after two outbreaks and considerable media publicity some cooling towers in Glasgow were poorly maintained and drew attention to the inadequate control of drift from cooling towers. ${ }^{14}$

\section{Conclusion}

The study of geographical variation in the incidence of legionnaires' disease provides a powerful basis for tracing the environmental sources of infection on a community basis. The methodology used in this study is conceptually straightforward (though technically demanding), but information on location of cooling towers, residence of patients, and populations in small areas is often not available.

In conclusion, this study shows that non-outbreak (or "sporadic") infection may arise from cooling towers and that such infection cannot be assumed to be acquired from the domestic environment or from hot water systems. This is encouraging as the scope for preventing non-outbreak infection is greater if control measures can be focused on the limited number of cooling towers rather than the much larger number of complex hot water systems in a community.

We thank the environmental health department of Glasgow District Council and Mr G Barr for support with the cooling tower survey; the hospital consultants and general practitioners for providing information; the information and statistics division of the Common Services Agency for unpublished data on hospital admissions based on Scottish morbidity records; the Greater Glasgow Health Board and the Pneumonia Research Trust for financial support; the $B M \mathcal{A}$ 's referees for helpful suggestions; Mrs Karen Ferguson for clerical help; and Mrs Lorna Hutchinson for preparing the manuscript.

\section{Appendix}

CASE DEFINITION OF LEGIONNAIRES' DISEASE

In probable cases of legionnaires' disease patients had a clinical history of an acute pneumonia or acute lower respiratory tract infection and culture of the organism and/or (for Legionella pneumophila only) (a) a fourfold rise (or fall) in titre to at least 64 but no other clinical diagnosis, or $(b)$ a static titre of 256 or more but no other clinical diagnosis, or (c) positive direct fluorescence antibody test result in respiratory secretions or tissue when using specific reagents, or $(d)$ legionella antigen detected in urine. Other patients were categorised as possible or unlikely cases (criteria not shown).

1 Bartlett CLR, Macrae AD, Macfarlane JT. Legionella infections. London: Edward Arnold: 1986.

2 Band JD, Fraser DW. Legionellosis. In: Reeves DS, Geddes AM, eds. Recen advances in infection. 2. Edinburgh: Churchill Livingstone, 1982:101-17.

3 Kuritsky JN, Reingold AL, Hightower AW, Broome CV. Sporadic legionellosis in the United States 1970-1982. In: Thornsberry C, Bellows A, Feeley JC, Jacubowski W, eds. Proceedings of 2nd intermational symposium. Washington: American Society for Microbiology, 1984:243-5.

4 Redd SC, Cohen ML. Legionella in water: What should be done? fAMA 1987;27:1221-2.

5 Ad-hoc Commitee. Outbreak of legionellosis in a community. Lance 1986;ii:380-3.

6 Bhopal RS, Fallon RJ. Geographical epidemiology of legionnaires' diseases in Glasgow: a preliminary report. Communicable Diseases (Scotland) Unit Weekly Report 1988:22 (17):7-11:22(18):2.

7 Bhopal RS. A surver of laboratory services for the diagnosis of legionnaires' disease in Scotland. Health Bull (Edinb) 1990;48:288-93.

8 Fallon RJ, Abraham W'H. Polyvalent heat-killed antigen for the diagnosis of infection with L.egionella pneumophila. F Clin Pathol 1982;35:434-8. 
9 Fallon RJ. Laboratory diagnosis of legionnaires' disease. London: British Medical Association/Association of Clinical Pathologists, 1981. (Broadsheet 99.)

10 Fallon RJ, Abraham WH. Legionella infections in Scotland. fournal of Hygiene (Cambridge) 1982;89:439-48.

11 Wilkinson HW, Brake BJ. Formalin-killed versus heat-killed Legionella pneumophila serogroup 1 antigen in the indirect immunofluorescence assay for legionellosis. I Clin Microbiol 1982;16:979-81.

12 Pastoris MC, Ciarrochi S, Di-Capua A, Temperanza AM. Comparison of phenol- and heat-killed antigens in indirect immunofluorescence test for phen- and hat for 780-3.

13 'Timbury MC, Donaldson JR, McCartney AC, et al. Outbreak of legionnaires' disease in Glasgow Royal Infirmary: microbiological aspects. Fournal of Hygiene (Cambridge) 1986;97:393-403.

14 Bhopal RS, Barr G. Maintenance of cooling towers following two outbreaks of legionnaires' disease in a city. Epidemiol Infect 1990;104:29-38.

15 General Register Office for Scotland. Postcode directory user guide. 1. General Register Office (Scotland), Edinburgh: 1986.

$16 \mathrm{Nimmo}$ AW. Review of computer mapping of health data. Health Bull (Edinb) 1989;47:40-53.

17 Breslow NE, Day NE. Statistical methods in cancer research. Vol 2. The design and analysis of cohort studies. Lyons: International Agency for Research on Cancer, 1987. (IARC Scientific Publications, No 82. )

18 Anonymous. How common is legionnaires' disease? Lancet 1983;i:103-4.

19 Bhopal RS, Fallon RJ. Variation in time and space of non-outbreak legionnaires' disease in Scotland. Epidemiol Infect (in press).

20 Devenay WT. Water supply from Loch Katrine to Glasgow and environs. Glasgow: Strathclyde Regional Council, (undated).
21 Bollin GE, Plouffe JE, Para MF, Hackman B. Aerosols containing Legionella pneumophila generated by shower heads and hot-water faucets. Appl Environ Microbiol 1985;50:1128-31.

22 Committee of Inquiry into Outbreak of Legionnaires' Disease in Stafford in April 1985. Second report. London: HMSO, 1987.

23 Klaucke DN, Vogt RL, La Rue D, et al. Legionnaires' disease: the epidemiology of 2 outbreaks in Burlington, Vermont 1980. Am f Epidemio 1984;119:382-91

24 Dondero TJ, Rendtorff RC, Mallison GF, et al. An outbreak of legionnaires' disease associated with a contaminated air-conditioning cooling tower. $N$ Engl f Med 1980;302:365-70.

25 Addiss DG, Davis JP, Wand PJ, McKinney RM, Gradus HS, Martins RR. Two cases of community-acquired legionnaires' disease: evidence fo association with a cooling tower. $\mathcal{F}$ Infect Dis 1989;159:572-5.

26 Westminster Action Committee. Broadcasting House legionnaires' disease. London: Westminster City Council, 1988.

27 Addiss DG, Davis JP, La Venture M, Wand PJ, Hutchinson MA, McKinney RM. Community-acquired legionnaires' disease associated with a coolin tower: evidence for longer-distance transport of Legionella pneumophila. Am F Epidemiol 1989;130:557-68.

28 Bovallius A, Roffey R, Henningston E. Long-range transmission of bacteria. Ann N Y Acad Sci 1980;353:186-97.

29 Muder RR, Yu VL, Woo AH. Mode of transmission of Legionella pneumophila. A critical review. Arch Intern Med 1986;146:1607-12.

30 Stout JE, Yu VL, Muroca P. Legionnaires' disease acquired within the homes of two patients. Link to the home water supply. $\mathscr{J} A M A$ 1987;257:1215-7.

(Accepted 13 November 1990)

\title{
Underprivileged areas and health care planning: implications of use of Jarman indicators of urban deprivation
}

\author{
Robin J Talbot
}

Abstract

Objective-To analyse critically the use of the Jarman underprivileged area index in health care planning and distribution of resources.

Design - The original derivation of the score was examined and evidence to support criticisms of the use of underprivileged area scores examined.

Main outcome measures-Discrepancies between areas classified as deprived according to the index and areas known to require government funding; the extent of the bias towards family practitioner areas in London; and how the results of using the Jarman index compared with those when another deprivation index based on different indicators was used.

Results-The use of electoral wards as geographical areas for which deprivation payments are made is unsatisfactory as the wards vary considerably in size. Of the 20 district health authorities with the highest underprivileged area scores in England, 12 were in London, and four of the six family practitioner committee areas with the highest scores were in London. No health authority or family practitioner committee area in the Northern region had one of the top 20 or 10 scores respectively. When an alternative deprivation index was used to determine the allocation of resources to doctors there was considerable variation compared with the Jarman index.

Conclusion-The Jarman index underprivileged area score is an inappropriate measure to use for health care planning and distribution of resources. There is a need for a revised measure for allocating deprivation payments to general practitioners.

\section{Introduction}

The Jarman score for underprivileged areas is a measure of general practitioners' workload. As well as the recent prominence as a trigger for special payments to general practitioners the Jarman underprivileged area index has been used as an indicator of urban deprivation. It has also been used in health service planning, where it was put forward as a measure to help in the allocation of resources in the discussions taking place before the publication of Working for Patients in 1989.

In this paper I trace the development of the Jarman index and examine some criticisms and wider issues affecting measures of urban deprivation.

The 1981 Acheson committee, in their review of primary care in London, collected evidence about the social characteristics of the inner London population (such as how many elderly people there were living alone) and its need for primary care. ${ }^{2}$ Replies and evidence to the committee formed the basis of a questionnaire that was distributed by Jarman in 1981 to a national $10 \%$ sample of general practitioners selected from a commercial mailing list. ${ }^{3}$ Much of the later work emanating from Jarman's research rests on responses to the single question:

Below is a list of factors which evidence suggests contribute to the pressure of work on general practitioners. Based on experience in your own practice, could you please score each factor on a scale from 0 (no problem) to 9 (very problematical) according to the degree to which it increases workload or contributes to the pressure of work when it is present. Those factors which you do not mark will not be included in our final calculations.

Jarman gave attention to service factors in his 1983 paper, but it was "social factors alone... [that were] used to measure workload according to the general practitioner's assessments." 3 Ten such social indicators are taken into account in the calculation of the underprivileged area score.

A weighting procedure was adopted for calculating the underprivileged area score according to the average scores given in response to the above question. Table I gives the average score for each factor. To validate the index a matching procedure took place that compared maps showing areas of greatest workload or pressure compiled by local medical committees with those of Jarman's underprivileged area scores for the same geographical areas. ${ }^{4}$ In five family practitioner committee areas there was agreement on all but $6.3 \%$ of the wards. According to Jarman, variations in the method of calculating the scores has little effect on the ranking of ward scores.

The measure quickly gained the attention of health
Education, Doncaste

College, Doncaster

Robin J Talbot, PHD,

senior lecturer

$B M 7$ 1991;302:383-6 